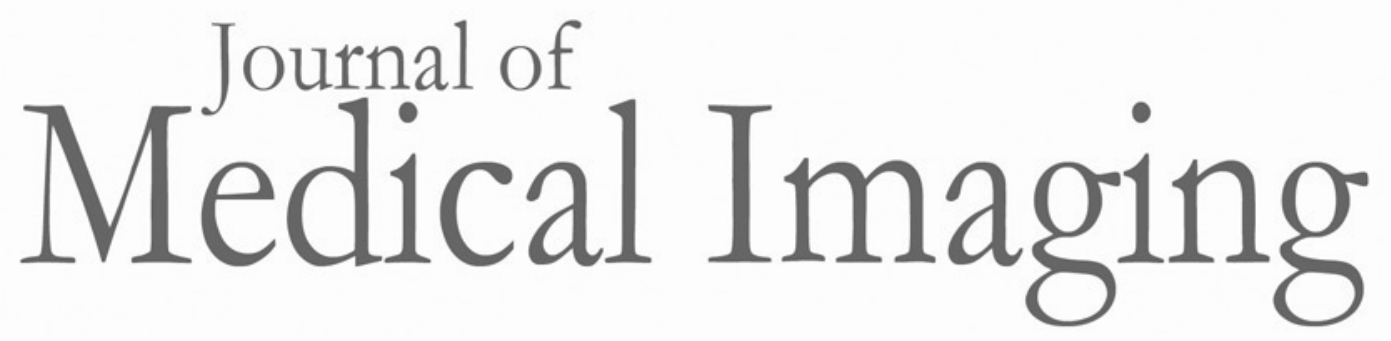

Medicallmaging.SPIEDigitalLibrary.org

\title{
Updates and Changes with JMI
}

\author{
Maryellen Giger
} SPIE. Maryellen Giger, "Updates and Changes with JMI," J. Med. Imag. 4(3), 030101 (2017), 


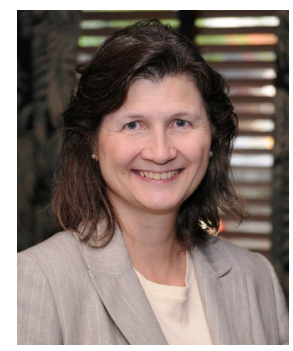

\section{Updates and Changes with JMI}

In January 2018, I am honored to begin a one-year term as president of SPIE, and thus, I am required to step down as the editor-in-chief of the Journal of Medical Imaging for the 2018 calendar year. Professor Norbert Pelc has been appointed by the SPIE Board of Directors to serve as JMI editor-in-chief for the year 2018, and he has graciously agreed to take the helm. Dr. Pelc is professor of bioengineering and radiology at Stanford University where he served as chair of the Department of Bioengineering, and his primary research interests are in the physics, engineering, and mathematics of diagnostic medical imaging and its applications, with a focus on computed tomography (CT). Professor Pelc is a member of the National Academy of Engineering, as well as a Fellow of SPIE, the American Association of Physicists in Medicine (AAPM), the International Society for Magnetic Resonance in Medicine (ISMRM), and the American Institute of Medical and Biological Engineering (AIMBE). Professor Pelc is very familiar with JMI, having been one of the driving forces behind its creation and having served as an advisory editor for JMI since its inception in 2014. I and SPIE are grateful to Professor Pelc for undertaking this leadership role and know that the journal will be in great hands.

At this time, I would also like to give an update on JMI. To date, JMI has published a total of 324 papers (60 in 2014,
84 in 2015, 105 in 2016, and 75 year to date in 2017), including the research of investigators from 45 different countries.

Five special sections have been published since JMI began publication in 2014 , on the following topics:

- Digital Pathology

- Development, Challenges, and Opportunities of Positron Emission Tomography

- Medical Image Perception and Observer Performance

- Radiomics and Imaging Genomics

- Pioneers in Medical Imaging: Honoring the Memory of Robert F. Wagner

Five special sections are currently in progress for upcoming issues of $\mathrm{JMI}$, on the following topics:

- Visions of Safety: Perspectives on Radiation Exposure

- Radiomics and Deep Learning

- Quantitative Imaging Methods and Translational Developments: Honoring the Memory of Dr. Larry Clarke

- Image-Guided Procedures, Robotic Interventions, and Modeling

- Medical Image Perception and Observer Performance

JMI is successful due to its dedicated associate editors, who come from across the world and contribute imaging expertise from academia, industry, and government, as well as the effective and efficient SPIE staff. I am greatly appreciative of their service to the journal.

$\mathrm{JMI}$ is included in leading abstracting and indexing databases, including PubMed, PubMed Central, Scopus, the Emerging Sources Citation Index (ESCl) in the Web of Science, Inspec, Embase, and Ei Compendex.

As always, I welcome your feedback on JMI.

Maryellen Giger Editor-in-Chief 